\title{
Performative Schizoid Method: Performance as Research
}

\section{Cover Page Footnote}

Thank you to Funen Art Academy and particularly Kristine Kemp for hosting me during my work on Becoming Iris. Thank you to artist Pernille Kragh for allowing me to borrow her plumes. Thank you for valuable comments and support from the anonymous reviewers and my colleagues at Roskilde University. 
Across the human and social sciences, it is argued that academic research should move toward and incorporate exploratory, experimental, inventive, creative, and artistic practice in research. From psychology, Mary Gergen and Kenneth Gergen advocate for a performative social science which "plays with purpose." ${ }^{1}$ Sociologist John Law argues for developing methodologies that are sensitive to the vague and ephemeral, suggesting that poetic and artistic practices may lead the way. ${ }^{2}$ From organization studies, Barbara Czarniawska insists on a social science that is sensitive to the polyphony of the world. ${ }^{3}$ Archaeologist Michael Shanks points out that widely separated fields of life and experience need connecting and that creative work, performance and design have crucial roles to play in these aspirations. ${ }^{4}$ Geographer Nigel Thrift contends that in order to capture the traces of the multitude of unknown entities that inhabit the world, inventive and experimental approaches are needed. ${ }^{5}$ These voices agree that academia needs creativity, sensibility, and inventiveness, but they also insist on the primacy of methodological reflexivity and awareness. Research methods are knowledge-creating and world-making practices; this is pointed out both by performance scholars and scholars from extended transdisciplinary fields. Research methods are important because they are intricately intertwined with knowledge-making and thus shape lives, societies, and worlds. ${ }^{6}$ The same scholars argue that new research methods need to be developed in order to build societal and global visions. One of the directions in which these and other scholars point is toward the Arts. Research informed by and based on the arts produces information and experiences that rational and objectivist methods cannot. ${ }^{7}$ Art is seen as a fruitful resource for generating sensitive and insightful academic research. ${ }^{8}$

Regardless of this orientation toward the arts, even scholarly literature, which advocates for methodological invention and experimentation, frames this experimentation in an instrumental and goal-oriented manner. One of the main differences between art and scholarly research is the role and expectation of rationality in the process of research. In academia a method is commonly something that is applied to a specific problem. This engenders a version of research and method that is goal-oriented and problem-driven.

In this article, I endeavor to carve out space in research for projects and methods that are more loosely defined and not necessarily goal-oriented or problem-driven. As pointed out by Celia Lury and Nina Wakeford, many inventive methods explicitly draw 
attention to the importance of "working with" methods - referring to the role of formgiving, craft and imagination. ${ }^{9}$ A method can be inventive, they assert, if it can be deployed to lure materials into posing their own problems. ${ }^{10}$

I propose that materials can pose their own problems if researchers would deemphasize predefinition of problems. This might make way for a research that is allowed to lead to uncontrollable outcomes-where materials may emerge in eventful and surprising ways. In other words, I call for research that draws on one of the fundamental qualities of artistic practice: its emergent nature. Engaging with academic research in ways that are open to emergence, to the unforeseen and unplanned, is challenging. It goes against centuries of rationalist thought, and also clashes with a contemporary notion that research must be useful.

....in recent years, there has been a tendency to argue that social science must be more practical, policy-oriented, and so on, a tendency which risks losing touch with wild ideas completely; it is the kind of social science that does not understand the basic point that it is producing a kind of intelligibility which 'can only confirm the prevailing views within those institutions that generated the data' (Rawls 2002:54) and in fetishizing the values of methodological rigour seems to me to miss a large part of the point of social science by purposefully going about deadening itself (Law 2005) when that is both pointless and unnecessary. ${ }^{11}$

To counteract this "deadening" tendency in an incessant reproduction of existing knowledge, a methodology needs to be crafted that can articulate the value of the unpredictable, unforeseen, and emergent. The performative schizoid method is such a maneuver. The performative schizoid method is a methodological strategy developed in order to make space for the unpredictable and unforeseen in academic research.

Non-representational theory, developed by cultural geographer and political scientist Nigel Thrift, is a strong advocate for this type of approach. Non-representational theory - flagged by some to be the "natural" successor to postmodern and poststructuralist thought - urges scholars to engage both in and with creative and artistic practice, and to do so in a manner that is restless and willfully immature. ${ }^{12}$ This form of engagement pushes limits and may lead to renewal, and the expressive power of the performing arts is invoked for this purpose. Thrift states, "I want to pull the energy of the performing arts into the social sciences in order to make it easier to 'crawl out to the edge of the cliff of the 
conceptual.' To see what will happen. To let the event sing you."13 Performance is seen as the best fit means to obtain a necessary "kind of poetics of the release of energy that might be thought to resemble play." 14 Researchers are urged to engage in artistic and creative practice: we need to "get in touch with the full range of registers of thought." 15

So this is where I stand: at the edge of the cliff of the conceptual. And as you will see, I am wearing plumage borrowed from an artist.

\section{Outline of Article}

I propose a methodological invention that engages performance as research. The method will be detailed through a presentation of its central, theoretical inspiration and main concepts. The method draws on Deleuze and Guattari's schizoanalysis and the performative approach to identity found in postmodern psychology. The performative schizoid method is related to the rich tradition of qualitative studies, particularly ethnography and auto-ethnography, but the method also differs from these in its attempt to enact imagined and fictional realities.

The theoretically driven account of the performative schizoid method is followed by a description of the method through its use in a research project called Becoming Iris: Developing a Performative Schizoid Method. The project was carried out during a threemonth visiting scholarship at a Danish visual arts academy and its objective was to enquire into arts-based knowledge creation. Becoming Iris uses a performative schizoid method that engages with and accesses aesthetic forms of knowledge, learning, and understanding. The project seeks to explore forms of working that are emergent; where the outcome is not defined in advance; and these forms are less prescriptive than predefined goal-oriented forms of engagement and modes of existence in research.

Following this investigation of method, I then present four pieces of creative work produced in the Becoming Iris project. The pieces were each created in a performative schizoid mode of research, and are thematically related, described and presented successively. There is a visual piece, an audio piece, a piece of concrete poetry, and a video.

The next section of the article picks up on the theme of borrowed feathers, one which emerges in the four produced pieces. The fable of the vain jackdaw prancing around 
in borrowed feathers pretending to be a peacock is discussed in relation to the performative schizoid method. The fable and the method are contrasted for their different stances on the possibility of multiplicity.

In the concluding section, I assert that the performative schizoid method succeeds in challenging rationalist and goal-oriented academic practice by allowing the researcher to explore unplanned and emergent research practices. In the Becoming Iris project, the figure of the schiz and the potential for postmodern performative selves support the researcher in creating and engaging with situations of unplanned production, which in turn results in surprising testimonials from this uncalculated engagement.

\section{Schizoid}

One way of disturbing goal-oriented instrumental rationality is to work with a strong figure or principle of the uncontrollable, unconscious, and emergent as valuable. Such a figure is provided by Deleuze and Guattari's schizoanalysis, as it is developed in Anti-Oedipus and A Thousand Plateaus.

Deleuze and Guattari develop the notion of schizoanalysis in opposition to psychoanalysis. Schizoanalysis creates accounts that are not modeled on the psychoanalytical understanding of psyche or society as a continuous Oedipal playing out of family relations. Basically, the idea is to disturb psychoanalytic approaches as the dominant model for therapy and as a key resource for cultural and social analysis. Deleuze and Guattari's schizoanalysis criticizes Freudian and Lacanian psychoanalyses for reducing psychological complexity to a one-model understanding that is too simplistic. ${ }^{16}$ Instead, they emphasize bifurcation, multiplicity, and complexity. ${ }^{17}$ Schizoanalysis heralds the uninhibited (creative) schizophrenic flow from the unconscious. Instead of the bottledup model of psychoanalysis - where the unconscious is seen as repressed, occasionally blurting out fantasies in illness or dreams - schizoanalysis favors seeing the unconscious as the revolutionary and productive force of desire. Schizoanalysis does not romanticize or celebrate schizophrenia as a mental illness, but Deleuze and Guattari suggest that the schizophrenic process makes it possible to see the "operations of the unconscious at their most primitive, functional level" - something they call desiring-production. ${ }^{18}$ In contrast 
to the Freudian view of the unconscious as representational theater, Deleuze and Guattari describe the unconscious as a real productive force: a desiring-productive machine. It hinges on schizoid processes as creative and generative, and on desire as a central

productive force. The schizophrenic process is a process of "free-form desire," 19 and schizoid delirium is "a constantly evolving grid of flows and breakflows (schizzes).",20 Schizzes are productive but have no predefined content. Desire is not goal-driven; it cannot be used consciously to attain goals or intents. It is "an unconscious libidinal investment:" non-specific, inclusive, nomadic, polyvocal and multiple. It cannot be assigned a goal or an end. ${ }^{21}$ This understanding thus heralds the unconscious-impulses of desire, lust, sexual drive, and other forces of intensity — which direct themselves where they will.

\section{Schizoid Method}

The performative schizoid method is inspired by Deleuze and Guattari's schizoanalysis. The full complexity of Deleuze and Guattari's understanding is not directly represented in the method, nor is the method an application of their schizoanalysis. The method works with the notion of the schiz, as a methodological manoeuvre, taking inspiration from Deleuze and Guattari's understanding of the schiz as a creative and productive force. In this method, the notion of schizophrenia is employed as an amplifier, a potential for a distorted enactment of reality; the method thus also traces the term schizoid to its etymological meaning of division, split, and cleavage. This implies that division and partiality are cultivated, not with sole reference to mentality but as a broader existential potential. The method is schizoid in the sense that certain split ways of interrelating, communicating, and acting are sought out, nourished, and cultivated.

Deleuze and Guattari developed schizoanalysis as a counterpoint to psychoanalysis but - as evidenced by, for example, their emphasis on the unconscious and desire - their understanding still draws heavily on a Freudian understanding of the human mind. Deleuze and Guattari challenge the notion of the repressed unconsciousness. Instead, unconsciousness is articulated as a free-forming production of desire. This understanding, however, still hinges on the centrality of the unconscious. Interestingly, in poststructuralist and postmodern psychology, the role of this unconsciousness is substantially reduced. ${ }^{22}$ 
Attention is directed instead at relationally enacted selves - at performative selves. The performative schizoid method draws on the figure of schizoid flow, but it also pulls the trope of the schiz toward poststructuralist, postmodern psychological theory, which questions convictions, beliefs, and ideas that are fundamental to psychoanalysis.

\section{Performative Schizoid Method}

In performance studies as well as in psychology, the notion of the performative refers to the conviction that social reality and identity positions are continuously enacted. A strong exponent of this approach is Judith Butler, who uses the term performativity to point out that there is no natural way of being male or female. Subjectivities, identities, and social realities are enacted repetitively, but these are routine enactments. ${ }^{23} \mathrm{We}$ might perceive continuity and substance in everyday life in relation to human behavior, but this does not mean that things are static; there is always the potential for disturbance of different sorts. A radical theoretical point drawing on Nietzsche is that there is "no doer behind the deed." This implies that there is no self before the performance of self. The performance of self constitutes the self. A performative notion of subjectivity posits that the subject is non-essentialist and protean. This implies that the subject constantly creates itself: identity is seen as a result of an ongoing process. ${ }^{24}$

At an individual level, the performative schizoid method works from the insights of performance studies as well as poststructuralist, postmodern social psychology. In other words, we are not core selves but act from multiple identity positions, which are constituted by the relations we engage in, by our situatedness. This orientation toward relational becoming connects well with the nomadic thought of Deleuze and Guattari, their interest in bodily forces and the qualitative transformations of these forces. ${ }^{25}$ Regardless of the emphasis that Deleuze and Guattari place on the unconscious, I posit that the schizoid and the performative may be combined productively. The method is compatible with the spirit of the rhizomatic and nomadic. ${ }^{26}$

The performative schizoid method plays with a nomadic and rhizomatic multiplication of the self. Multiplicity plays itself out in partially connected relational selves. ${ }^{27}$ The performative schizoid method focuses on the idea that identity, perception of 
self and other, and modes of action and communication, may shift by introducing consciously devised "schizoid" elements, working voluntarily with splitting and fragmentation. In a very basic sense, performative implies that something is like a performance. ${ }^{28}$ So in a very basic sense the performative schizoid method engages the schiz in a performance-like manner. The method uses the notion of the abundant schizoid flow as a counterpoint to conceptions of the researcher self as a coherent and homogenous unity. The method seeks to use split, fragmentation, and multiplicity as a resource for research. The purpose is to circumvent the researcher's conventional positioning, to experiment with and explore alternative research positions, and to discover how "coming to know something" is done differently from other modes of engagement and vantage points. The performative schizoid method suggests that the researcher attempt to engage in and develop "new" or different subject vantage points from which research can then be carried out. Is this at all possible?

It seems that actors and performers can, in fact, cultivate, distort and amplify specific aspects and dimensions of their emotional and behavioral capabilities and build characters and enact realities based on those aspects. This is done, for example, in method acting, which has subsequently been transferred to method writing. ${ }^{29}$ But is it possible to create relevant and insightful research from inauthentic, fictional positioning? Will it not always be layers of her or himself that the researcher enacts and encounters?

The method radically reformulates the positioning of the researcher in relation to the researched. The researcher creatively, imaginatively and productively puts him or herself in play in the research process, but not in a way where the researcher self is psychoanalytically excavated and confessionally ${ }^{30}$ analyzed. Instead, the researcher engages in a schizoid flow of association, creation, and imagination. Identity may be at play and in play, but more as a desiring-productive and relational force than as a fixated and stable position. This is why I use the term identity positioning rather than identity position. Ongoing and continuous processes of identification take place, but without permanent and stable identity.

The performative schizoid method is a research method where the researcher is actively and creatively involved in the research process and project. The researcher might also use props, clothing, and location as artefacts to mediate creativity and imagination in 
seeking out new modes of action and communication. The method seeks to create and generate insight through open-ended schizo-inspired modes of engagement. The research object is not specified clearly in advance, but emerges in dialogue with the situation and through sites of communication and production. Rather than addressing one specific problem, the research is a loose gathering of interests that are shaped throughout the process of engagement, and whose shape continues to evolve as it is woven into academic accounts.

The performative schizoid method is a methodological maneuver which makes it possible for the researcher to cultivate new (and unplanned) modes of action. The method is interested in action, in the actual doing of research. The performative schizoid method engages with thinking "method" where the production of realities takes center-stage. Methods are an active intervention in the taking-place of events. ${ }^{31}$ The method solicits a mode of research that not only aims at representation, but is itself a targeted process, practice, and performance. It is a non-representational mode of research.

\section{Similar Approaches?}

The performative schizoid method is related to the rich tradition of qualitative studies - particularly ethnography and auto-ethnography-but the method also differs from these approaches in its aim of enacting imagined and fictional realities. The method bears great resemblance to what anthropologists and sociologists of an ethnographic bent have been doing for decades: immersing themselves in cultures in order to be able to provide an insider's insight; well-known examples are John Van Maanen's study of police organizations and Loic Wacquant's studies of boxing. ${ }^{32}$ The method also relates to studies that insist on making place for the personal in ethnographic accounts-with notable examples being the work of Ruth Behar and Renato Rosaldo-and in relation to performance as described by Tammi Spry, Ronald Pelias and Norman Denzin. ${ }^{33}$

One manner in which the proposed method distinguishes itself from these studies is that it does not cultivate the authentic first-person voice; on the contrary, it seeks to disturb this voice, unsettle it, and to push it into unknown territory-perhaps even to distort it. 
The notion of a performative schizoid method is based on the idea that the researcher uses her or himself as a source of knowledge and understanding, but the method also pushes this insight further: instead of delving deep inside the emotional and personal landscape of the researcher, inquiry is pushed outwards, away from the self.

A contemporary project that is methodologically related to the performative schizoid method is Kingston University Professor Will Brooker's enactment of David Bowie personas for a year. ${ }^{34}$ Brooker performs by dressing as Bowie, listening to music he would have listened to, and eating food he had eaten, etc. ${ }^{35}$ One apparent difference between the Bowie project and the performative schizoid method is that the Bowie project relates to a real-life character. The performative schizoid method does not latch itself onto a specific character. It enacts something without necessarily having the facticity of a realworld person as point of reference.

Another related project, which engages with developing knowledge, learning, and understanding from fictional and make-believe modes of engagement, is the activist performance art project Sisters Academy, where performance artists take over the leadership of real world schools, in order to promote more sensuous and poetic forms of education and communication. In this example, theatricality and performativity are used as strategies for experiencing everyday life anew. ${ }^{36}$

This kind of inquiry produces process knowledge. The research does not necessarily seek to produce directly measurable results - even though such results may emerge; the research neither seeks to explain specific aspects of reality nor does it attempt to represent specific aspects of reality directly. The research seeks to engage with and cultivate space for the unplanned and emergent in research. In instrumental terms, the research might be justified for generating insight into research processes, the intersections between research and art, creativity, alternative forms of organization of research, and of research as a hybrid practice.

\section{Becoming Iris}

I think of the performative schizoid method as a method that can be used in many situations, practices, and events. My first exploratory engagement with the method was in a specific project called Becoming Iris, where I explored arts-based knowledge-creation during a three-month visiting scholarship at the Funen Art Academy, a small, independent 
visual art academy in Denmark (April-June 2016). Becoming Iris is a methodological experiment that seeks to develop a performative schizoid method of inquiry into arts-based knowledge creation. Becoming Iris engages with performance as an extreme knowledgecreating practice, where the creation of art is integrated into research. In the project I sought to develop a new subject position, a new mode of inquiry, represented by the transformative intention of Becoming Iris. The purpose was to circumvent my ordinary self-positioning as a researcher and to experiment with a position(ing) that is embedded in and engaged in aesthetic, visual practice - where this is the rationale, the logic, the primary modus and form of expression, and which derives from this practice the freedom of non-instrumental exploration. The rhizomatic multiplication and disturbance of self in Becoming Iris was an attempt to access the creative process of aesthetic forms. The project sought to facilitate connection with more sensitive, perhaps slower, and definitely less instrumental and less goal-oriented forms of engagement and modes of existence in research. The project was simultaneously an attempt to perform a contraposition to production pressure and instrumental approaches to writing in academic work, as expressed in the dictums Publish or Perish! Perform or Else!

In the Becoming Iris performative schizoid mode of engagement, four productions were made, and the four productions are included as companion pieces to this article: (1) a visual work called Big Eyed Bird; (2) a piece of concrete poetry called Big Beaked Bird; (3) a spoken-word audio recording of this same piece; and (4) a video called Borrowed Plumes. These productions were created in performative schizoid situations where I, as a researcher, attempted to engage in my own distorted version of Deleuze and Guattari's “desiring-production." Quite simply, I translated this notion into a very simple maxim of doing something without purpose, playing around, and just making something. In the first of these situations, I cleared my desk, sorted out old notes, looked in my cupboard, found some feathers, and made Big Eyed Bird.

The four productions were created in a mode of research that seeks to engage a performative schizoid method, a Becoming Iris-rhizomatic approach, which for me implies working in an emergent way across multiple media and forms of expression, and with no explicit pre-formulated objectives. It has been an intended goal to work in an open and receptive manner. Engaging in such production methods is an exercise of associative 
thinking and doing. The method is loose. Its purpose is, in a manner of speaking, to be purposeless. This does not mean that it is without structure. It is temporally organized: there is an allotted amount of time wherein it is possible for the researcher to be engaged. Working in this way can be challenging; the value of the research may be questioned: is the work relevant? Does it lead to anything?

The emergent Becoming Iris productions are traces of a process. They may be discussed as artifacts in their own right, and may be analyzed for content and aesthetic expression, but their role and function within the present project is to show that something unplanned and emergent took place. Their value is that they bear witness to a process and of a range of situations. Viewing them as witnesses of a process rather than as discrete objects is in accordance with an orientation that is found as a point of convergence between schizoid thinking and performance studies: there is "a shared concern to shift the focus from thinking in terms of discrete objects and subjects, toward a concern with processes, relations and happenings." 37

\section{What is the Value of Purposelessness?}

In a sense the method may be seen as an antidote to what Thrift terms "reductionist, rationalist social science obsessed with prediction and control and the will to explain everything." The Becoming Iris project and its production of the four bird and feather works is an example of a research project where the unconscious, uncontrollable, and emergent becoming are cultivated. This is facilitated by working within a very loosely defined framework.

A way of working emerged in the project where the materials at hand as well as impressions and intensities were allowed to prompt the process. There was no plan, but a flow of intensity, association, and translation. It was an emergent improvisational act of engagement that was materially embedded and directed through a medium.

What was the result?

-A series of work having to do with birds and feathers.

- How did feathers and birds find their way into Becoming Iris? 
I have no specific, personal affection for or history with birds or feathers. I never owned a pet bird. I don't care much for birds. Following Deleuze and Guattari, we might say that the factory of my unconscious produced the work. Are the emerging feathers and birds reminiscent of forgotten memories? Of sea gulls screeching from high up above in the empty, grey North Atlantic sky that was my primary point of orientation before I could crawl? I do not know-but the productions that emerge in Becoming Iris revolve around feathers and birds.

\section{Four Becoming Iris Desiring-Productions}

\section{Production 1: Big Eyed Bird}

Big Eyed Bird is a visual piece which shows a roughly painted bird with an open beak, a large eye and tail feathers. The medium is white acrylic painting on black paper. The feathers and a movable plastic disc-eye have been glued on. The work is carried out with materials that are at hand (black paper, plastic disc, and feathers), and its production feels like doodling. But it also works with a specific kind of emotional intensity: attempting to transfer emotional intensity to the paper, to demonstrate this with the pressure of the brushstrokes and the open-mouthedness of the beak.

\section{Production 2: Big Beaked Bird}

Big Beaked Bird is a piece of concrete poetry. Text is printed on white paper, with pencil added after print. The text and pencil lines resemble a bird, somewhat of the same shape as the bird in the visual image Big Eyed Bird. The work is initiated in an attitude of a kind of free-writing activity, roughly seeking to translate the image of Big Eyed Bird into text, initially not thinking too much about the particular word choice. The first visual image Big Eyed Bird is translated in an associative manner to text, describing but also allowing for invention. The text tries to put into words some of the emotion manifested in the brush strokes of the first image. Through this process, the notion of the borrowed feathers 
emerges somewhere in the translation of the image of a bird with feathers, which materially has nothing to do with acrylic painting or plastic eyes, and which is drawn from two different kinds of birds (in other words, they are borrowed). The notion of borrowed feathers is subsequently translated to Borrowed Plumes in the last performance-based production, the video piece.

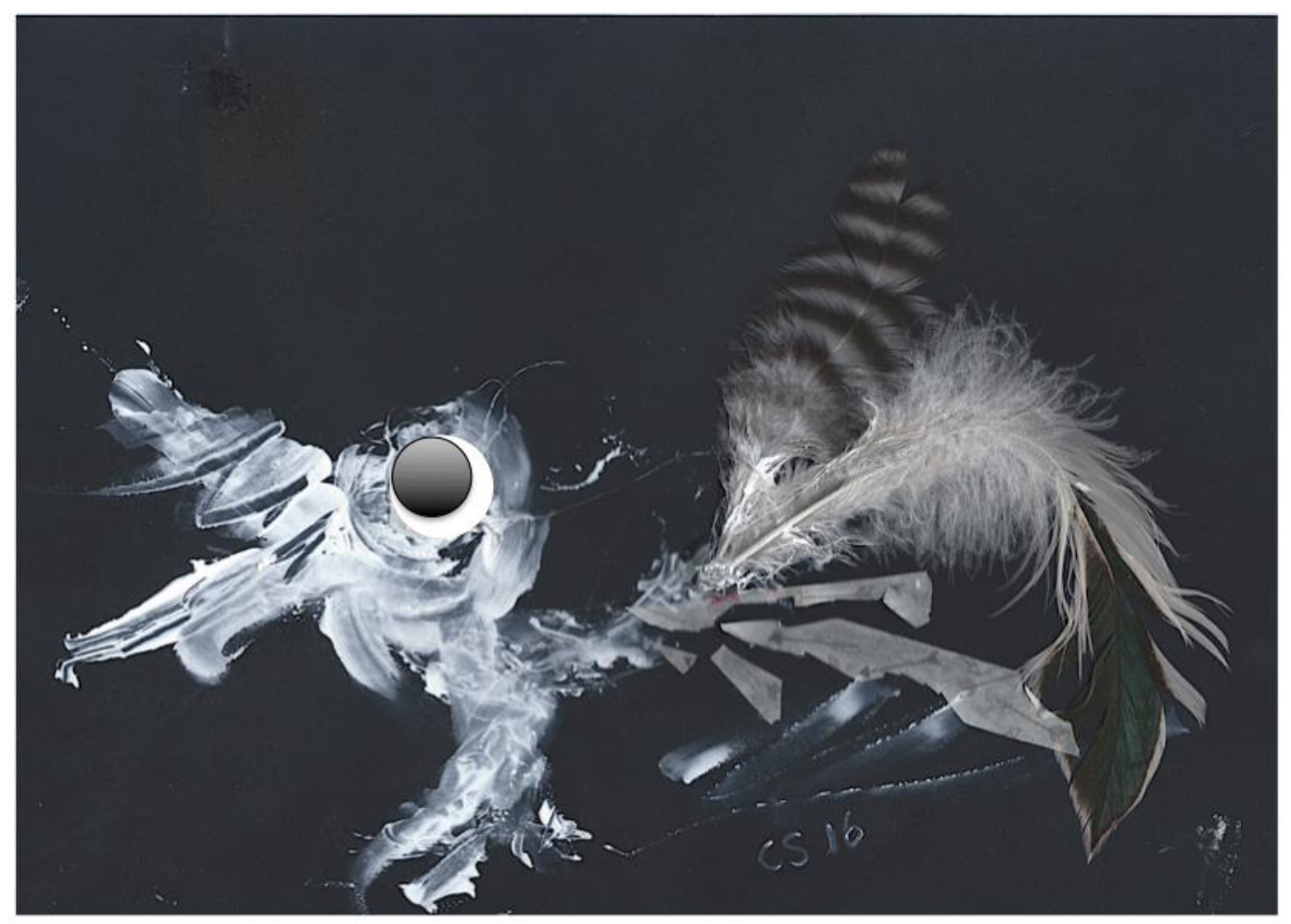

\section{Production 1: Big Eyed Bird (visual image, detail)}

Materials: White paint and feathers, a movable plastic disc-eye and glue on black paper. // This first production is translated into productions 2 and 3 . 


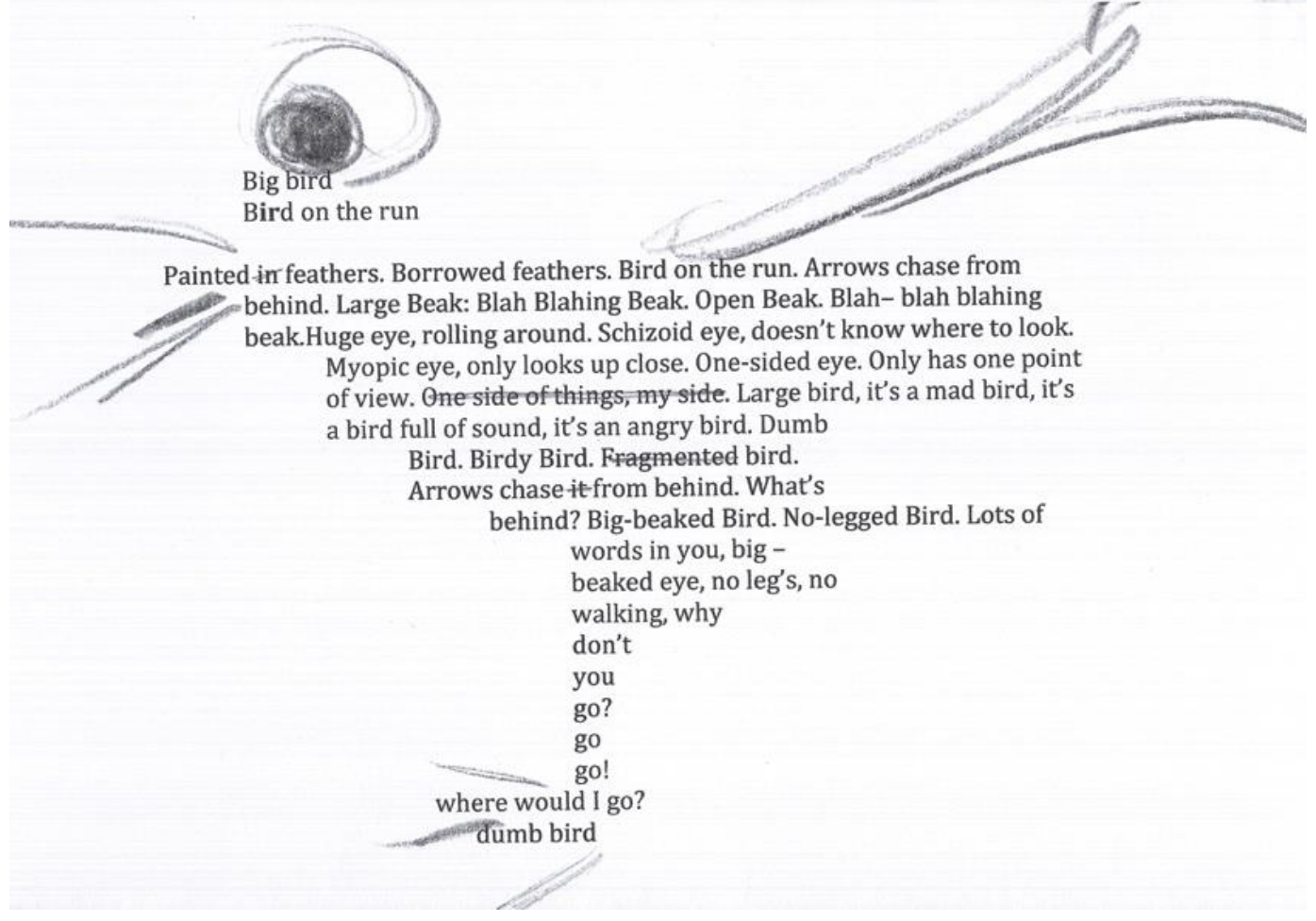

\section{Production 2: Big Beaked Bird (concrete poetry)}

Materials: text, chalk. // This is a piece of concrete poetry evoked via association with Big Eyed Bird (Production 1).

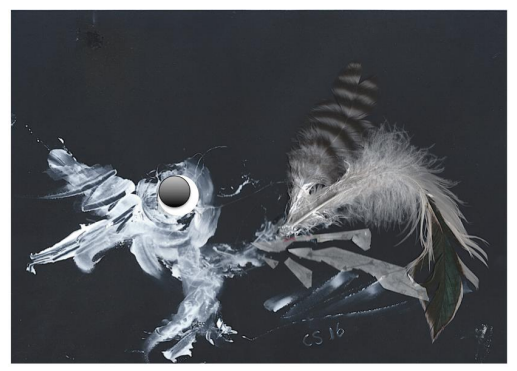

\section{Production 3: Big Beaked Bird (audio recording)}

Materials: Voice. // Spoken-word version of the visual images Big Eyed Bird (Production 1) and Big Beaked Bird (Production 2).

[Big Beaked Bird Audio (Production 3) intended to be listened to while looking at Big Eyed Bird Image (Production 1)] 


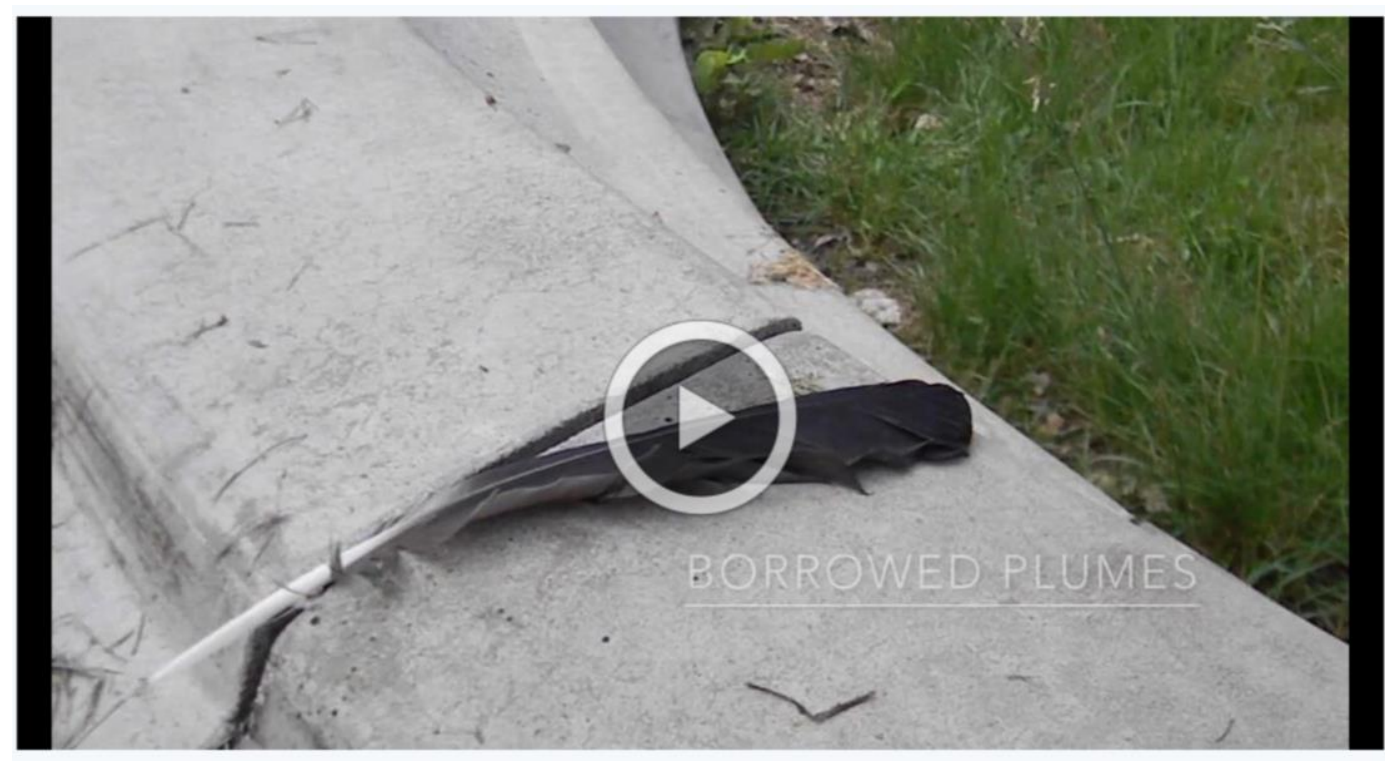

Production 4: Borrowed Plumes (video).

Materials: a borrowed artist's dress, Glorup Landscape Garden, researcher.

Borrowed Plumes is a video piece. The video shows me wearing a dress, which I borrowed from a fine arts student at the Funen Art Academy. As part of an academy excursion to a Danish landscape garden, I wanted to push myself toward Becoming Iris: to engage in a performative schizoid method of inquiry. For some reason the dress became a potential figure for this.

\section{From my Field Notes, April 23, 2016:}

Borrowed Feathers. The title came during the textual exploration of the Big Eyed Bird. This idea of borrowed feathers is a wonderful notion. It encompasses and communicates some of what the Becoming Iris project is about. The performative schizoid method may be seen as a strategy of borrowing feathers. Of becoming in borrowed feathers. My time at the art school, working there, being there as a researcher, is a covert way of trying to sneak in, like the cuckoo, to a nest that is not mine, like an oversized egg hoping to be hatched with the others. It is a process 
of borrowing feathers, of stepping into appearances, of appearing as something else, something somehow borrowed. Borrowed Feathers.

I was intent on doing something with the dress and the excursion to the landscape garden, but did not want to show up at the excursion wearing the dress. So I decided I would do my own encounter with Glorup, with dress and camera.

Borrowed Plumes is a performative schizoid method experiment in the sense that I tried to enact a new researcher position and positioning by wearing an artist's dress, wearing borrowed plumes, imagining myself making art. I took time to carry out the somewhat strange and purposeless activity of going to the designated landscape garden, alone, with a borrowed dress and a camera. I encountered the garden with the dress, and in the dress.

I also did desk research. I looked into the cultural history of borrowed feathers:

\section{From my Field Notes, June 8, 2016:}

My association transitioned from painted feathers to borrowed feathers, which is also frequently called Borrowed Plumes, a wiki search tells me. So I find a beautiful etching, which I treasure and save in a folder on my computer and as an image in my consciousness of a crow-like bird prancing with peacock feathers. And I find the fable. And it is not an uplifting fable. It is not a story of postmodern, poststructuralist fluid or performative identities. (...) No, this is a fable warning us not to pretend. Do not pretend to be a peacock, when in fact you are a jackdaw. Do not pretend to be an artist, when in fact you are an academic researcher.

\section{Between Borrowed Plumes and Postmodern Performativity}

We are what we are. The notions of borrowed plumes and a performative schizoid method stand in sharp contrast to each other. They build on radically different perceptions

of the human subject. The fable of the borrowed plumes symbolically tells people not to 
dress up as anything other than what they are, not to present themselves as peacocks when actually they are jackdaws. If you pretend to be something other than what you are, things will go poorly for you. You may even be cast out. This fable conveys what, broadly speaking, can be termed an essentialist understanding: people have a given, determined nature. There is an essence that makes people (or birds) what they are. For example, in psychoanalysis there exists an identifiable determining content to a person. ${ }^{38}$ The performative schizoid method, in contrast, departs from this kind of unity-in-essence in its orientation toward "endless connections, nonexclusive disjunctions, non-specific conjunctions, partial objects and flows." 39 The performative schizoid method draws on anti-essentialism, as it is consistently argued across intellectual traditions of postmodernism, post-structuralism, post-foundationalism and post-Enlightenment thinking. The performative schizoid method builds on the idea that there is no essence or given, pre-determined nature that defines people. This relates to the concept of performativity and a constructionist approach to the human subject.

These two figures of thought bring with them radically different possibilities for becoming. The essentialist approach tends to be deterministic in the sense that a lot of things are given; they are defined by biology, or by upbringing, for example. Antiessentialist approaches build on the conviction that everything in principle could be different. Becoming different is possible. In fact, not only is it possible; it takes place all the time: “it's always a multiplicity, even in the person who speaks or acts. We are all groupuscules." 40

\section{Conclusion}

This article introduces the performative schizoid method as research methodology, one which works with unpredictability and emergence as a premise. The relevance of the method is supported by a compilation of transdisciplinary voices, arguing for the inclusion of creative, exploratory, experimental, inventive, and artistic practice in research. The method challenges rationalist and goal-oriented academic practice, and has the potential to stimulate creativity and invention in academic work. 
The performative schizoid method is developed with primary theoretical inspiration from Deleuze \& Guattari's schizoanalysis, which places desire center-stage in productive schizoid flows and break-flows. In the method, this force is explored as a way of making space in research for uncontrollable and emergent becoming. The method is unfolded in relation to a specific research project, Becoming Iris, which explores what comes out of unplanned performative schizoid research situations. In Becoming Iris, the figure of the schiz and the potentiality of postmodern performative selves support the researcher in creating and engaging with situations of "unplanned production." The four Becoming Iris productions are presented as examples of emergent situations of unplanned desiringproduction.

The performative schizoid method allows the researcher to explore unplanned and emergent research practices in the project Becoming Iris. Thus, the method is successful in relation to this specific project. The method, however, may be difficult to grasp, because it seriously challenges how we conventionally think of research and research methods. The nature of the method is loose. Its purpose is to be purposeless. It is useful for seeking out and creating space for uncontrolled and emergent practices and production in research, but this simultaneously challenges the researcher to endure the void, to make the researcher available to the unknown schiz. It may be difficult to grasp: what is its research object? It might also lead to questions of what the value of the research truly is. Is the work relevant? Does it lead to anything?

1 Mary M. Gergen and Kenneth J. Gergen, Playing with Purpose: Adventures in Performative Social Science (California: Left Coast Press, 2012).

2 John Law, After Method: Mess in Social Science Research (London and NewYork: Routledge, 2004).

3 Barbara Czarniawska, Narratives in Social Science Research (London: Sage, 2004).

4 Michael Shanks, The Archaeological Imagination (CA:Left Coast Press 2012), Mike Pearson and Michael Shanks, Theatre/Archaeology (London: Routledge, 2001).

5 Nigel Thrift, Non-representational Theory: Space, Politics, Affect (London: Routledge, 2008). 
6 Celia Lury and Nina Wakeford, Inventive Methods: The Happening of the Social (Oxon: Routledge, 2012).

7 J. Gary Knowles and Ardra L. Cole, Handbook of the Arts in Qualitative Research (California: Sage Publications, 2008). Patricia Leavy, Method Meets Art: Arts-Based Research Practice (New York and London: The Guilford Press, 2009). Lorri Neilsen, Ardra L. Cole and J. Gary Knowles. The Art of Writing Inquiry (Canada: Backalong Books, 2001).

8 Michael Schwab and Henk Bergdorff, The Exposition of Artistic Research: Publishing Art in Academia (Amsterdam: Leiden University Press, 2014), $13 \mathrm{f}$.

$9 \quad$ Lury and Wakeford, 19.

10 Ibid., 12.

11 Thrift, 18

12 Phillip Vannini, "Non-representational Research Methodologies: An Introduction," in Non-representational Methodologies: Re-envisioning Research, ed. Phillip Vannini (New York and London: Routledge, 2015), 5.

13 Thrift, 12.

14 Ibid.

15 Ibid.

16 Ian Buchanan. Reader's Guides: Deleuze and Guattari's 'Anti-Oedipus': A Reader's Guide 1, (London: Continuum, 2008), 28.

17 Jon McKenzie, Perform or Else: From Discipline to Performance, (New York: Routledge, 2001), 52.

18 Buchanan, 36.

19 Eugene W. Holland, Deleuze and Guattari's Anti-Oedipus: Introduction to Schizoanalysis, (London: Routledge, 2002), 100.

20 Buchanan, 34.

21 Holland, 100.

22 Vivien Burr, An Introduction to Social Constructionism, (London and New York: Routledge, 1995). 
23 Judith Butler, Bodies that Matter: On the Discursive Limits of "Sex," (New York and London: Routledge, 1993).

24 Britta Timm Knudsen, "It's Live. Performativity and Role-playing," in Performative Realism: Interdisciplinary Studies in Art and Media, eds. Rune Gade and Anne Jerslev (Denmark: Museum Tusculanum Press, 2005), 270.

25 Elizabeth Grosz, Chaos, Territory, Art: Deleuze and the Framing of the Earth, (New York: Columbia University Press, 2008), 3.

26 Brian Massumi, foreword to A Thousand Plateaus: Capitalism and Schizophrenia, by Deleuze Gilles and Félix Guattari, (Minneapolis/London: University of Minnesota Press, 1987), xiii.

27 John Law, After Method: Mess in Social Science Research (London and NewYork: Routledge, 2004). Mike Michael, Reconnecting Culture, Technology and Nature: From Society to Heterogeneity, (London and New York: Routledge, 2000).

28 Richard Schechner, Performance Studies: An Introduction, $3^{\text {rd }}$ edition, (New York: Routledge, 2013), 123.

${ }^{29}$ Robert Olen Butler, From Where You Dream (Groven Press 2007), Klaus H. Frederiksen, Method Design (Masters Thesis, Performance Design 2015).

30 John Van Maanen, Tales of the Field: On Writing Ethnography, (Chicago: University of Chicago Press, 1988).

31 Ben Anderson and Paul Harrison "The Promise of Non-Representational Theories," in Ben Andersen and Paul Harrison, Taking-Place: Non-Representational Theories and Geography (Surrey: Ashgate, 2010), 23.

32 John Van Maanen, "Fieldwork on the Beat," in Varieties of Qualitative Research, John Van Maanen, J. M. Dabbs, R. R. Faulkner (New York: Sage Publications, 1982). John Van Maanen, Tales of the Field (Chicago: Chicago University Press, 1988). Loic Wacquant, Body \& Soul: Notebooks of an Apprentice Boxer (Oxford: Oxford University Press, 2004).

${ }^{33}$ R. Behar, The Vulnerable Observer: Anthropology that Breaks Your Heart (Boston: Beacon Press, 1996). Norman K. Denzin, "Interpretive Autoethnography," in Handbook of Autoethnography, eds. Stacy Holman Jones, Tony E. Adams and Carolyn Ellis (Walnut Creek: Left Coast Press, 2013). Ronald J Pelias, Performance: An Alphabet of Performative Writing (Walnut Creek: Left Coast Press, 2014) and "Writing Autoethnography: The Personal, Poetic and Performative as Compositional Strategies," in Handbook of Autoethnography, eds. Stacy Holman Jones, Tony E. Adams and Carolyn Ellis (Walnut Creek: Left Coast Press, 2013). R. Rosaldo, "Grief and a Headhunter's Rage," in Culture and Truth: The Remaking of Social Analysis, ed. R. Rosaldo (Boston: 
Beacon Press, 1989). Tami Spry, Body, Paper, Stage: Writing and Performing Autoethnography (Walnut Creek, California: Left Coast Press, 2011).

34 Kingston University London. "Researcher Professor Will Brooker Raises the Roof as David Bowie at Kingston University Ziggy Stardust tribute concert." Posted Thursday, 12 May, 2016.

http://www.kingston.ac.uk/news/article/1654/12-may-2016-researcher-professor-willbrooker-raises-the-roof-as-david-bowie-at-kingston-university-ziggy-stardust/.

35 Gani Aisha, "Ch-Ch-Ch-Changes: Academic to Spend Year as David Bowie's Many Personas," The Guardian, August 18, 2015.

https://heguardian.com/music/2015/aug/18/ch-ch-ch-changes-academic-to-spend-yearas-david-bowies-many-personas.

36 Gry Worre Hallberg and Olav Harsløf, "Experiencing Everyday Life Anew: Applied Theatrical and Performative Strategies," in Handbook on the Experience Economy, eds. Jon Sundbo and Flemming Sørensen (Cheltenham, UK/Northampton, USA: Edward Elgar, 2013).

37 Laura Cull, introduction to Deleuze and Performance, ed. Laura Cull (Edinburgh: Edinburgh University Press, 2009), 3.

38 Burr, 5.

39 Buchanan.

40 Gilles Deleuze, quoted in Buchanan, 23. 